\title{
Spatial and temporal village-level prevalence of Plasmodium infection and associated risk factors in two districts of Meghalaya, India
}

Anne Kessler', Badondor Shylla2,3, Upasana Shyamsunder Singh4, Rilynti Lyngdoh, Bandapkupar Mawkhlieng ${ }^{2}$, Anna Maria van Eijk 1 , Steven A. Sullivan ${ }^{1}$, Aparup Das ${ }^{6}$, Catherine Walton ${ }^{4}$, Mark L. Wilson? Jane M. Carlton ${ }^{1,8^{*}+}$ and Sandra Albert ${ }^{2,3^{*}+}$

\begin{abstract}
Background: Despite declining incidence over the past decade, malaria remains an important health burden in India. This study aimed to assess the village-level temporal patterns of Plasmodium infection in two districts of the north-eastern state of Meghalaya and evaluate risk factors that might explain these patterns.

Methods: Primary Health Centre passive malaria case data from 2014 to 2018 were analysed to characterize villagespecific annual incidence and temporal trends. Active malaria case detection was undertaken in 2018 and 2019 to detect Plasmodium infections using PCR. A questionnaire collected socio-demographic, environmental, and behavioural data, and households were spatially mapped via GPS. Adult mosquitoes were sampled at a subset of subjects' houses, and Anopheles were identified by PCR and sequencing. Risk factors for Plasmodium infection were evaluated using bivariate and multivariate logistic regression analysis, and spatial cluster analysis was undertaken.

Results: The annual malaria incidence from PHC-based passive surveillance datasets in 2014-2018 was heterogenous but declining across villages in both districts. Active surveillance in 2018 enrolled 1468 individuals from 468 households (West Jaintia Hills) and 1274 individuals from 359 households (West Khasi Hills). Plasmodium falciparum prevalence per 100 people varied from 0 to $4.1 \%$ in the nine villages of West Jaintia Hills, and from 0 to $10.6 \%$ in the 12 villages of West Khasi Hills. Significant clustering of P. falciparum infections [observed $=11$, expected $=2.15$, Relative Risk $(R R)=12.65 ; p<0.001$ ] was observed in West Khasi Hills. A total of 13 Anopheles species were found at 53 houses in five villages, with Anopheles jeyporiensis being the most abundant. Risk of infection increased with presence of mosquitoes and electricity in the households [Odds Ratio $(O R)=1.19$ and 1.11], respectively. Households with reported animals had reduced infection risk $(\mathrm{OR}=0.91)$.

Conclusion: Malaria incidence during 2014-2018 declined in all study villages covered by the passive surveillance data, a period that includes the first widespread insecticide-treated net campaign. The survey data from 2018 revealed a significant association between Plasmodium infection and certain household characteristics. Since species
\end{abstract}

\footnotetext{
*Correspondence: jane.carlton@nyu.edu; sandra.albert@phfi.org

${ }^{\dagger}$ Jane M. Carlton and Sandra Albert are co-senior authors

${ }^{1}$ Center for Genomics and Systems Biology, Department of Biology, New

York University, New York, NY 10003, USA

${ }^{2}$ Indian Institute of Public Health-Shillong, Shillong, Meghalaya 793001,

India

Full list of author information is available at the end of the article
}

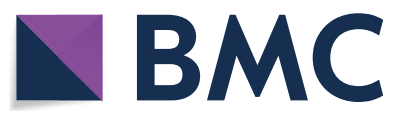

(c) The Author(s) 2021. This article is licensed under a Creative Commons Attribution 4.0 International License, which permits use, sharing, adaptation, distribution and reproduction in any medium or format, as long as you give appropriate credit to the original author(s) and the source, provide a link to the Creative Commons licence, and indicate if changes were made. The images or other third party material in this article are included in the article's Creative Commons licence, unless indicated otherwise in a credit line to the material. If material is not included in the article's Creative Commons licence and your intended use is not permitted by statutory regulation or exceeds the permitted use, you will need to obtain permission directly from the copyright holder. To view a copy of this licence, visit http://creativeco mmons.org/licenses/by/4.0/. The Creative Commons Public Domain Dedication waiver (http://creativecommons.org/publicdomain/ zero/1.0/) applies to the data made available in this article, unless otherwise stated in a credit line to the data. 
of Plasmodium-competent mosquito vectors continue to be abundant, malaria resurgence remains a threat, and control efforts should continue.

Keywords: Subpatent Plasmodium infections, Anopheles mosquito abundance, Declining incidence, Malaria elimination

\section{Background}

In 2018, India (4\%) was one of five countries that accounted for close to $50 \%$ of all malaria cases worldwide, along with Nigeria (25\%), Democratic Republic of the Congo (11\%), Mozambique (5\%), and Uganda (4\%) [1]. The regions of India with high malaria incidence have more recently been found in the east and northeast of the country, with six states contributing roughly three-quarters of cases [2]. In the seven northeastern states, malaria is generally declining [3], but continues to impede the equitable health improvement and socioeconomic development of the region. Historically, the state of Meghalaya has reported more than $20 \%$ of cases annually in this region [2]. Among the Meghalaya districts endemic for malaria, the majority of recent cases have been observed in the Garo Hills, West Khasi Hills, and West Jaintia Hills [4]. Malaria cases and fatalities increased in Meghalaya from 2012 to 2015, but declined in 2016 [4]. While anti-malarial drug therapy could be responsible for the decline, the causality is not clear, as artemether-lumefantrine (AL) against Plasmodium falciparum was introduced in the northeastern states of India in 2013 and has not changed since then $[2,3]$. Alternately, the decline could be related to the $>941,000$ long-lasting insecticidal nets (LLINs) distributed throughout the state for the first time in mid-2016 by the Meghalaya state malaria control programme.

Other than unpublished findings from Meghalaya government reports, no data on recent changes in incidence are available, nor on risk factors associated with malaria in this region. This study assessed the village-level prevalence of Plasmodium infection, explored geo-spatial patterns, and evaluated village-level risk factors in two districts of Meghalaya.

\section{Methods}

\section{Study setting and ethical approval}

Data were gathered from two districts of Meghalaya state: West Khasi Hills and West Jaintia Hills. The districts were selected based on the 2016 Annual Parasite Index (API) reported for all 11 Districts (Fig. 1). Although the API was highest in the Garo Hills at this time, these districts were not selected for active case detection due to logistical issues and safety concerns in the surrounding area(s). Two types of malaria data were analysed: passive case data obtained from the district Primary Health
Centres (PHC) during 2014-2018 and active case surveillance during 2018 and 2019.

Ethical approval for the study was obtained from the Institutional Review Boards (IRBs) of Martin Luther Christian University, Shillong, Meghalaya, India and New York University, New York, NY, USA. Written informed consent was obtained from all the participants who were 18 years of age or older. Assent was obtained for the participants aged 7-17 years in addition to parental consent.

Data sources and management for passive case detection Malaria case data were collected from laboratory logbooks and Accredited Social Health Activists (ASHA) reports for January 2014 to December 2018 at the Barato PHC (West Jaintia Hills), and January 2015 to December 2018 at the Nonglang PHC (West Khasi Hills). Case data for Kyrdum, a West Khasi Hills village in the Nonglang PHC catchment area surveyed here by active surveillance, was not available and, therefore, not included in the dataset. These datasets include village-level malaria surveillance details on the number of blood samples tested and the number that were positive for either Plasmodium and/or $P$. falciparum infection. Laboratory-confirmed Plasmodium infections were those with parasites in the peripheral blood smear as detected through microscopy or through an antigen-detecting Rapid Diagnostic Test (RDT) (Source: NVBDCP guidelines 2013).

\section{Sampling design for active case surveillance}

Active case surveillance was conducted in a subset of West Jaintia Hills and West Khasi Hills villages in 2018 and 2019 using a community-based survey. Similar to the district selection, the Barato PHC from West Jaintia Hills and the Nonglang PHC from West Khasi Hills were chosen for sampling based on API relative to all other PHCs within the respective districts. Nine of the 20 villages under the Barato PHC (West Jaintia Hills), and 12 of 32 villages under the Nonglang PHC (West Khasi Hills) were selected for surveying based on API, logistics, and representation across both the PHCs and their regional sub-centres. To achieve the calculated study sample size, $50 \%$ of households in each village were selected using the Probability Proportion to Size (PPS) technique at random from the sampling frame provided by the ASHA in each village. Additional households were sampled on a need basis to fulfill target enrollment numbers. All eligible 


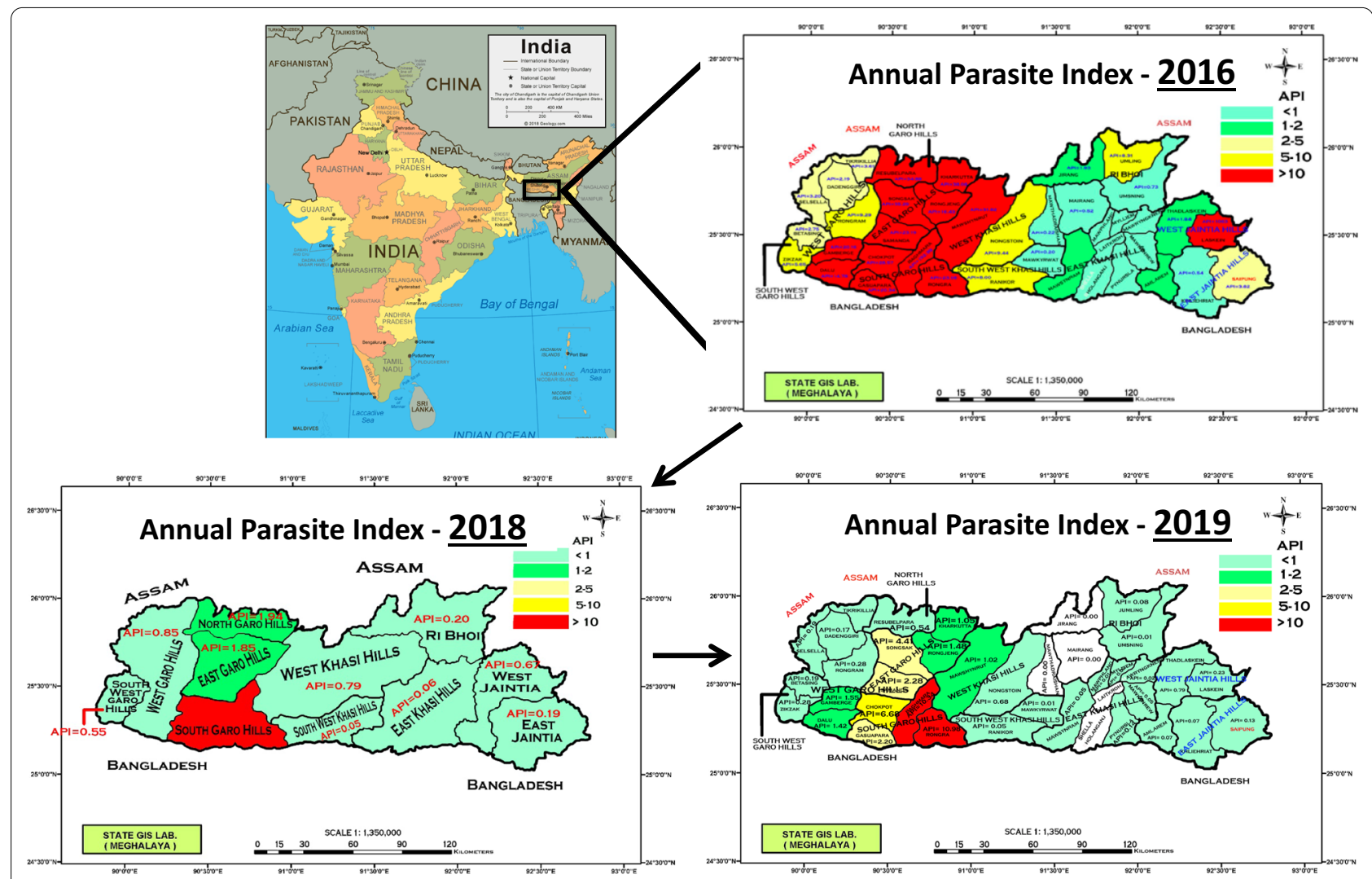

Fig. 1 Malaria Annual Parasite Index (API) map of Meghalaya state in northeastern India by district for 2016, 2018 and 2019

consenting individuals from each selected household were enrolled; inclusion criteria were defined as individuals between the ages of 1 and 69 years with no immediate health risks and apparent full comprehension of the study procedures. In the event that not all household members were present at the time of initial enrollment, a repeat visit was made on the same day to capture all eligible participants.

\section{Survey data collected from community survey}

Data were collected from April to November 2018 and May to September 2019 in both study regions, i.e., West Khasi Hills and West Jaintia Hills (Table 1). All households with enrolled study participants were spatially mapped via Global Positioning System (GPS) readings. Answers to a household survey were given by one resident, most commonly the 'head of household, followed by individual surveys administered in the local language to each individual resident of the household, consisting of a pre-tested, structured interview with mostly closeended questions. Demographic information (age, gender, education, occupation), medical history (fever, episodes of malaria, antimalarial use in the past year, other complaints), travel history over the past two weeks, and data on use of malaria prevention methods (e.g., insecticidetreated nets (ITNs), repellents, coils) were also obtained. Daily behaviours and practices were also surveyed, with a focus on those that may put individuals at risk of infection, such as participation in outdoor activities during the evening. Parents or caretakers responded to some questions on behalf of their child(ren) for questions where the child did not have the knowledge or understanding to provide an answer.

\section{Blood sample collection and processing}

Blood was taken by finger prick with a disposable lancet. A bivalent RDT (FalciVax) and an ultra-sensitive RDT (Abbott Alere) were used for point-of-care detection of $P$. falciparum and/or $P$. vivax and $P$. falciparum infections, respectively. A small blood volume was taken into a microvette, and post-centrifugation the blood components were separated and stored at $-80 \mathrm{C}^{\circ}$. DNA was extracted from the RBCs. Additionally, blood was spotted on to Whatman filter paper and smeared onto glass slides. The thin blood smears were fixed in methanol and dried prior to Giemsa staining and subsequent qualitative and quantitative evaluation by light microscopy. Laboratory-confirmed Plasmodium 
Table 1 Population of West Jaintia Hills and West Khasi Hills villages and the number of households and residents enrolled in the study during 2018 and 2019

\begin{tabular}{|c|c|c|c|c|c|c|c|c|}
\hline District & Villages & $\begin{array}{l}\text { Total } \\
\text { Population }\end{array}$ & $\begin{array}{l}\text { Total } \\
\text { Households }\end{array}$ & $\begin{array}{l}\text { Households } \\
\text { enrolled } \\
(2018) n(\%)\end{array}$ & $\begin{array}{l}\text { Individuals } \\
\text { enrolled } \\
(2018) \text { n (\%) }\end{array}$ & $\begin{array}{l}\text { Households } \\
\text { enrolled } \\
(2019) \mathrm{n}(\%)\end{array}$ & $\begin{array}{l}\text { Individuals } \\
\text { enrolled } \\
(2019) \mathrm{n}(\%)\end{array}$ & $\begin{array}{l}\text { New } \\
\text { Enrollees } \\
(2019)\end{array}$ \\
\hline \multirow{9}{*}{$\begin{array}{l}\text { West Jaintia } \\
\text { Hills }\end{array}$} & Barato A & 597 & 155 & 107 (69.03) & 389 (65.16) & $42(27.10)$ & 189 (31.66) & 70 \\
\hline & Barato B & 652 & 128 & $62(48.44)$ & $171(26.23)$ & $43(33.59)$ & $194(29.75)$ & 110 \\
\hline & Barato C & 465 & 99 & $65(65.66)$ & $196(42.15)$ & $40(40.40)$ & $173(37.20)$ & 81 \\
\hline & Barato E & 569 & 100 & $53(53.00)$ & 110 (19.33) & 0 & 0 & 0 \\
\hline & longkwang & 420 & 83 & $32(38.55)$ & $116(27.62)$ & 0 & 0 & 0 \\
\hline & Kynshur & 643 & 125 & $43(34.40)$ & $114(17.73)$ & 0 & 0 & 0 \\
\hline & Mukroh A & 500 & 100 & $60(60.00)$ & $178(35.60)$ & 0 & 0 & 0 \\
\hline & Mukroh B & 439 & 65 & $34(52.31)$ & $106(24.15)$ & 0 & 0 & 0 \\
\hline & Saba & 587 & 85 & 30 (35.29) & 88 (14.99) & 0 & 0 & 0 \\
\hline Total & & 4872 & 940 & 468 (49.79) & $1468(30.13)$ & $117(12.45)$ & $556(11.41)$ & 261 \\
\hline \multirow[t]{12}{*}{ West Khasi Hills } & Khyllemsangrin & 413 & 68 & $29(42.65)$ & $111(26.88)$ & $9(13.24)$ & 33 (7.99) & 4 \\
\hline & Kriangrin & 300 & 68 & $34(50.00)$ & $105(35.00)$ & 15 (22.06) & $42(14.00)$ & 6 \\
\hline & Kyndongnei & 187 & 32 & $25(78.13)$ & $133(71.12)$ & 0 & 0 & 0 \\
\hline & Kyrdum & 621 & 93 & $50(53.76)$ & 165 (26.57) & $13(13.98)$ & $48(7.73)$ & 15 \\
\hline & Langja & 723 & 122 & $16(13.11)$ & $20(2.77)$ & 0 & 0 & 0 \\
\hline & Mawlan B & 109 & 21 & $11(52.38)$ & 34 (31.19) & $6(28.57)$ & $6(5.50)$ & 2 \\
\hline & Mawsikar & 468 & 72 & 28 (38.89) & $99(21.15)$ & $4(5.56)$ & 14 (2.99) & 2 \\
\hline & Nonglang & 365 & 73 & $56(76.71)$ & 209 (57.26) & $24(32.88)$ & $65(17.81)$ & 13 \\
\hline & $\begin{array}{l}\text { Pyndeng- } \\
\text { sohstap }\end{array}$ & 47 & 10 & $5(50.00)$ & $19(40.43)$ & $2(20.00)$ & $7(14.89)$ & 1 \\
\hline & Siangra & 251 & 36 & $22(61.11)$ & $66(26.29)$ & $10(27.78)$ & $12(4.78)$ & 0 \\
\hline & Umthlu & 398 & 68 & $33(48.53)$ & $120(30.15)$ & $20(29.41)$ & $44(14.00)$ & 4 \\
\hline & Umwahlang & 552 & 85 & $50(58.82)$ & $193(34.96)$ & $2(2.35)$ & $7(1.27)$ & 0 \\
\hline Total & & 4434 & 748 & $359(47.99)$ & $1274(28.73)$ & $105(14.04)$ & $278(6.27)$ & 47 \\
\hline
\end{tabular}

infections were those with parasites in the peripheral blood as detected via RDT and/or Polymerase Chain Reaction (PCR) only (no infections were detected by microscopy).

\section{Species-specific PCR detection of Plasmodium parasites}

Plasmodium falciparum and/or P. vivax infections were detected in the community survey study participants by PCR amplification of concentrated DNA extracted from microvettes. Briefly, DNA was extracted using the QIAamp DNA mini kit (QIAGEN) and eluted in $50 \mathrm{ul}$ of distilled water. The total volume of DNA for each sample was concentrated using a Speed-Vac (Thermo Scientific) to $20 \%$ of the starting volume. Two novel genetic markers, Pvr47 present as 14 copies in the $P$. vivax genome, and Pfr364 present as 41 copies in the $P$. falciparum genome, were utilized in a single-step PCR as described [5] using $5 \mu \mathrm{l}$ of concentrated DNA. PCR amplicons were visualized by standard gel electrophoresis of the entire PCR reaction using ethidium bromide and UV light documentation.

\section{Mosquito capture methods}

Adult mosquitoes were collected using CDC light traps (John W. Hock, Gainesville, FL, USA) during August through November 2018 from two villages in West Khasi Hills ( 30 households) and three villages in West Jaintia Hills (23 households). One unbaited trap per night per household was hung to the roof or ceiling outside of the room where people sleep to capture human host-seeking mosquitoes. The collected mosquitoes were morphologically identified at the genus level under a microscope in the field, and all Anopheles spp. were stored individually in beam capsules and desiccated by storage with silica gel for subsequent species identification by PCR (and sequencing).

\section{PCR-based identification of Anopheles species}

DNA extracted from 161 individual adult mosquito specimens (QIAamp DNA Mini kit) was amplified using either the Internal Transcribed Spacer 2 (ITS2) region of ribosomal DNA (101 specimens) or a region of the mitochondrial cytochrome oxidase subunit I (COI) gene (60 specimens). The ITS2 primers were 
forward primer 5.8S (5'-TGTGAACTGCAGGACACA TG-3') and reverse primer $28 \mathrm{~S}$ (5'-ATGCTTAAATTT AGGGGGTA-3') [6, 7]. Each 25 ul reaction consisted of $1.5 \mu \mathrm{l}$ DNA template and $0.25 \mu \mathrm{l}$ Phusion HighFidelity DNA Polymerase with final concentrations of $1 \mathrm{X}$ HF Phusion buffer, $200 \mu \mathrm{M}$ [dNTPs], and $0.5 \mu \mathrm{M}$ primers. PCR conditions were: $98{ }^{\circ} \mathrm{C}$ for $30 \mathrm{~s}$ followed by 35 cycles of $98{ }^{\circ} \mathrm{C}$ for $10 \mathrm{~s}, 61{ }^{\circ} \mathrm{C}$ for $30 \mathrm{~s}$, and $72{ }^{\circ} \mathrm{C}$ for $30 \mathrm{~s}$, with a final extension at $72{ }^{\circ} \mathrm{C}$ for $5 \mathrm{~min}$. PCR products were purified using GeneElute ${ }^{\mathrm{TM}}$ PCR Cleanup kit (Sigma-Aldrich). Sanger sequencing was performed in the forward direction using the $5.8 \mathrm{~S}$ forward primer. The COI fragment was amplified using primers LCO-1490 (5'-GGTCAACAAATCATAAAGATATTG G-3') and HCO-2198 (5'-TAAACTTCAGGGTGACCA AAAATCA-3') [8]. Each 25 ul reaction consisted of $1 \mu \mathrm{l}$ of DNA template and $0.15 \mu \mathrm{l}$ of Invitrogen $(5 \mathrm{U} / \mu \mathrm{l})$ Taq DNA Polymerase with final concentrations of $1 \mathrm{X}$ (Thermo Scientific $^{\mathrm{TM}}$ ) buffer, $200 \mu \mathrm{M}$ [dNTPs] (Thermo Scientific $\left.^{\mathrm{TM}}\right)$, each primer at $0.16 \mu \mathrm{M}, 2 \mathrm{mM}\left[\mathrm{MgCl}_{2}\right]$, and $0.2 \mathrm{mg} / \mathrm{ml}$ [BSA]. The PCR conditions were $95{ }^{\circ} \mathrm{C}$ for 2 min followed by 35 cycles of $95{ }^{\circ} \mathrm{C}$ for $45 \mathrm{~s}, 55^{\circ} \mathrm{C}$ for $1 \mathrm{~min}$, and $72{ }^{\circ} \mathrm{C}$ for $1 \mathrm{~min}$, with a final extension at $72{ }^{\circ} \mathrm{C}$ for $7 \mathrm{~min}$. The PCR products were purified using EXOSAP, and Sanger sequencing was subsequently performed in the reverse direction using the HCO-2198 reverse primer.

Sequences were edited as necessary for accurate base calling, and primer sequences were removed using Geneious Prime ${ }^{\circledR}$ 2020.1.2 (http://www.geneious.com) [9]. ITS2 sequences were compared against the NCBI nucleotide database using BLAST. For COI, sequences were compared against the BOLD database (http:// www.boldsystems.org) [10] to determine Anopheles species identity. If the query search produced two species matches, the 'phylogenetic tree' generated by BOLD using public and private COI sequences was referred to in order to confirm the closest match. The sequences generated in this study were deposited in GenBank with Accession Numbers as follows: Anopheles jeyporiensis: MT863705 (COI), MT872791 (ITS2); Anopheles maculatus: MT863706 (COI), MT862759 (ITS2); Anopheles pseudowillmori: MT871948 (COI), MT872797 (ITS2); Anopheles nivipes: MT863711 (COI), MT872792 (ITS2); Anopheles philippinensis: MT872793 (ITS2); Anopheles barbirostris: MT863707 (COI)i; Anopheles dissidens: MT872790 (ITS2); Anopheles nitidus: MT863712 (COI), MT872789 (ITS2); Anopheles peditaeniatus: MT872794 (ITS2); Anopheles xui: MT871949 (COI); Anopheles vagus: MT872798 (ITS2); Anopheles splendidus: MT872799 (ITS2); Anopheles jamesii: MT871938 (COI).

\section{Statistical analysis}

Plasmodium infection prevalence per 100 people was calculated for each village included in the survey. Associations between demographic, environmental, and behavioral risk factors and village-level Plasmodium infection prevalence were determined using logistic regression analysis and odds ratios (OR) (95\% confidence intervals (CI)). Risk factors with significant associations were analysed using multivariate logistic regression to adjust for confounders. All data were analysed using Statistical Package of Social Sciences (SPSS) version 15.0 (SPSS Inc., Chicago, IL) and Stata version 14.4 (StataCorp, College Station, TX).

\section{Spatial cluster analysis}

SaTScan 9.6 software (https://www.satscan.org/) was used to identify significant spatial clustering of Plasmodium infection prevalence among the study villages. The statistical test employs a circular window to systematically search for significant spatial clusters over a defined geographic area. The radius of the window may vary from zero to a user defined upper limit, here defined as the geographic area that included $50 \%$ of the study region to allow for the detection of both small and large clusters [11]. Likelihood ratios were calculated, and p-values were derived by conducting Monte-Carlo replications of the dataset using the continuous Poisson model [12]. The number of individuals with Plasmodium infection in each village was defined as 'cases.' The total number of people sampled per village was defined as the 'population.'

\section{Results}

\section{Trends in malaria incidence from Meghalaya state data 2014-2018}

Analysis of government data obtained for West Jaintia Hills and West Khasi Hills indicated temporal patterns in malaria incidence that were similar across villages (Fig. 2). Most of the villages in West Jaintia Hills experienced increasing incidence in malaria cases (primarily $P$. falciparum) between 2014 and 2015 (2016 disaggregated village level data were not available), and declined thereafter, except in Barato A and Barato B, where case numbers continued to increase until 2017 (Fig. 2a).

For villages in West Khasi Hills, malaria incidence either decreased slightly or remained stable between 2015 and 2016 (2014 data were not available), except in Nonglang, Langja, and Khylleimsangrin, where incidence was still increasing until 2017 (Fig. 2b). A decline in incidence was observed for all villages between 2017 and 2018. Nonglang village reported the highest malaria incidence throughout the study period. 

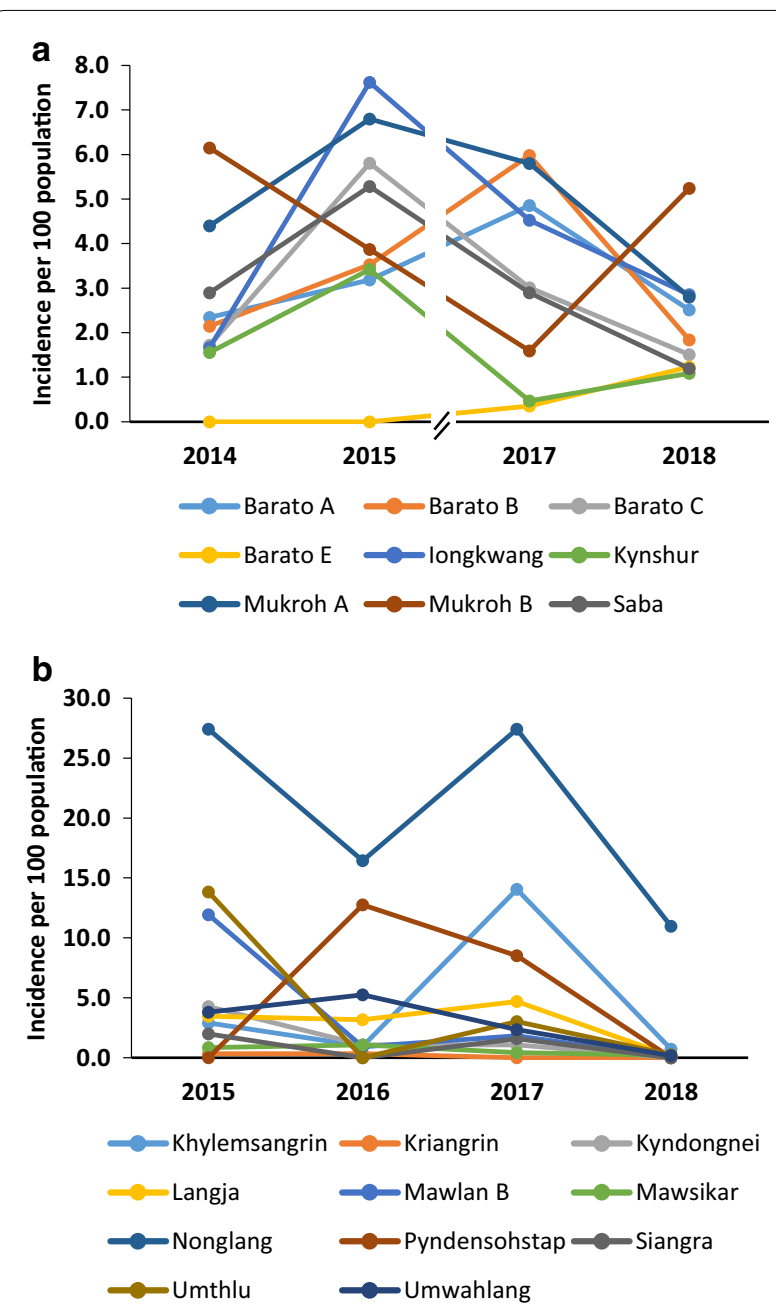

Fig. 2 Annual trend of malaria incidence from government health facilities in villages served by a Barato PHC, West Jaintia Hills from 2014 to 2018 (2016 not available), and b Nonglang PHC, West Khasi Hills from 2015 to 2018

\section{Village-level Plasmodium infection prevalence from active surveillance in 2018 and 2019}

A a total of 1468 individuals from 468 households were enrolled in the West Jaintia Hills, and 1274 individuals from 359 households were enrolled in the West Khasi Hills (Table 1). The village-level prevalence of $P$. falciparum infection identified through active surveillance in 2018 and as detected by PCR varied from 0 to $4.1 \%$ P. falciparum (16 PCR positive infections total) in the nine villages of West Jaintia Hills and from 0 to $10.6 \% P$. falciparum (17 PCR positive infections total) in the 12 villages of West Khasi Hills (Table 2). No P. vivax infections were identified. All 16 P. falciparum infections identified in the West Jaintia Hills came from a single village (Barato A), and of the 12 villages in West Khasi
Hills, $P$. falciparum infections were identified in six villages, with Siangra showing the highest prevalence (10.61\%; Table 2). Of the 33 P. falciparum infections identified by PCR in 2018, only the single infection identified in Umwahlang village WKH was also RDT positive. The village-level prevalence of $P$. falciparum infection identified through active surveillance in 2019 was $0 \%$ in all villages by all detection methods, i.e., microscopy, RDT, and PCR.

\section{Comparison of 2014-2017 PHC incidence with 2018 PHC and active detection estimates}

Further evidence of declining incidence comes from comparing PHC-based malaria incidence for 2014-2017 with PHC results and active surveillance for 2018 (Table 3). All but two villages experienced a decline from the PHCbased incidence for 2014-2017 (average) to that for 2018. This represented a $50 \%$ or greater reduction in some villages. Only Barato E and Mukroh B villages had a slight increase in 2018, primarily reflecting small or variable numbers. Active surveillance prevalences for each village in 2018 were generally also lower than the PHC average incidence for the preceding years, except for Barato A, Kriangrin, and Siangra, which increased slightly. This may reflect chance variation because of smaller numbers of active surveillance participants.

\section{Anopheles mosquitoes captured at participants' houses}

Light-trap samples from 30 houses produced 112 adult female Anopheles mosquitoes in West Khasi Hills (3.7 per trap-nights), where five species were identified (Table 4). In West Jaintia Hills, however, 23 houses that were sampled produced 12 species of Anopheles from only 49 female mosquitoes collected (2.1 per trap-nights). Interestingly, $A n$. jeyporiensis was the most abundant in both West Khasi Hills (1.9 per trap-night) and West Jaintia Hills (1.0 per trap-nights), even though it has not been frequently reported in recent studies in the region. Anopheles maculatus and An. pseudowillmori were more abundant in West Khasi Hills as compared to West Jaintia Hills. Additionally, many of the species associated with rice paddies, including those of the $A n$. annularis, $A n$. hyrcanus and $A n$. barbirostris groups, were only found in West Jaintia Hills, whereas, An. splendidus was captured solely in West Khasi Hills. The relative abundances of each species (Fig. 3) showed that there were few individuals for most species; however $A n$. jeyporiensis was abundant in both districts, as was An. maculatus in West Khasi Hills. More extensive sampling will be needed to produce reliable and meaningful estimates of species diversity in the area.

Surprisingly, two species that have not previously been reported in India, $A n$. xui and An. dissidens, were 
Table 2. 2018 village-level prevalence of Plasmodium infection

\begin{tabular}{|c|c|c|c|c|}
\hline District & Village & No. people enrolled & No. people PCR-pos & $\begin{array}{l}\text { Prevalence } \\
\text { per } 100 \\
\text { population }\end{array}$ \\
\hline \multirow[t]{9}{*}{ West Jaintia Hills } & Barato A & 389 & 16 & $4.11(2.14,6.08)$ \\
\hline & Barato B & 171 & 0 & $0(0,0.02)$ \\
\hline & Barato C & 196 & 0 & $0(0,0.02)$ \\
\hline & Barato E & 110 & 0 & $0(0,0.03)$ \\
\hline & longkwang & 116 & 0 & $0(0,0.03)$ \\
\hline & Kynshur & 114 & 0 & $0(0,0.03)$ \\
\hline & Mukroh A & 178 & 0 & $0(0,0.02)$ \\
\hline & Mukroh B & 106 & 0 & $0(0,0.03)$ \\
\hline & Saba & 88 & 0 & $0(0,0.04)$ \\
\hline Total & & 1468 & 16 & $1.09(0.56,1.62)$ \\
\hline \multirow[t]{12}{*}{ West Khasi Hills } & Khyllemsangrin & 111 & 3 & $2.7(0,5.72)$ \\
\hline & Kriangrin & 300 & 1 & $0.33(0,0.98)$ \\
\hline & Kyndongnei & 133 & 0 & $0(0,0.02)$ \\
\hline & Kyrdum & 165 & 0 & $0(0,0.02)$ \\
\hline & Langja & 20 & 0 & $0(0,0.16)$ \\
\hline & Mawlan B & 34 & 0 & $0(0,0.10)$ \\
\hline & Mawsikar & 99 & 0 & $0(0,0.03)$ \\
\hline & Nonglang & 209 & 1 & $0.48(0,1.42)$ \\
\hline & Pyndengsohstap & 19 & 0 & $0(0,0.16)$ \\
\hline & Siangra & 66 & 7 & $10.61(3.18,18.04)$ \\
\hline & Umthlu & 120 & 4 & $3.33(0.12,6.54)$ \\
\hline & Umwahlang & 193 & 1 & $0.52(0,1.53)$ \\
\hline Total & & 1274 & 17 & $1.33(0.7,1.96)$ \\
\hline
\end{tabular}

captured in West Jaintia Hills. Anopheles xui, a member of the An. hyrcanus group, has been described from China [13]. Anopheles dissidens, which is morphologically indistinguishable from An. barbirostris, is found elsewhere in mainland Southeast Asia [14].

\section{Village-level household characteristics}

The household characteristics that were analysed by village represent the village-specific proportion of households with each characteristic (Table 5; Table 6). In both districts, more than half of the households in each village were composed of 4-7 occupants. In West Jaintia Hills villages (Table 5), the percentage of houses with electricity varied from 0 to $92 \%$, while domestic water almost exclusively came from open wells/tanks (range: 97-100\%), and toilet availability varied considerably. However, in West Khasi Hills, village electricity access was generally higher (20-98\%), many households obtained water from an improved source, and the prevalence of household toilets was generally higher (Table 6). These same West Khasi Hills villages had a higher prevalence of houses constructed of wood/mud/thatch walls (59-100\%) than those in West Jaintia Hills (37-65\%).
Villages also differed in the prevalence of households with reported mosquitoes present and in their anti-mosquito practices. In West Jaintia Hills villages (Table 5), most people reported that mosquitoes were "always" present in the house (41-79\%), and virtually every household (98-100\%) had one or many ITNs. In addition, households in these villages more often used multiple malaria preventions, and virtually every household used a "public" health centre for fever treatment. In contrast, in West Khasi Hills villages (Table 6), a lower prevalence of houses reported that mosquitoes were "always" present ( $0 \%$ to $64 \%$ ), and the prevalence of one or more ITNs was lower $(75-100 \%)$. Fevers were more often treated at a "private" health facility.

\section{Village-level risk factors for Plasmodium infection}

For statistical analyses, any village with one or more residents who tested positive by PCR for Plasmodium infection in the 2018 active surveillance was designated as a Plasmodium-positive village. Bivariate logistic regression of all 21 villages comparing village-level infection $(\mathrm{Y} / \mathrm{N})$ with village-level prevalence of each covariate, here defined as percentage of households in the village 
Table 3 Annual village-level malaria incidence and prevalence per 100 people for nine villages of West Jaintia Hills, and 11 villages of West Khasi Hills for 2014-2018

\begin{tabular}{|c|c|c|c|c|}
\hline \multirow[t]{2}{*}{ District } & \multirow[t]{2}{*}{ Village } & \multicolumn{2}{|l|}{ Malaria incidence } & \multirow{2}{*}{$\begin{array}{l}\text { Prevalence } \\
\text { CSCMi (2018) }\end{array}$} \\
\hline & & $\begin{array}{l}\text { PHC-Based 3-yr. Avg.* } \\
(2014-2017)\end{array}$ & PHC-Based (2018) & \\
\hline \multirow[t]{9}{*}{ West Jaintia Hills } & Barato A & 3.46 & 2.51 & 4.11 \\
\hline & Barato B & 3.89 & 1.84 & 0 \\
\hline & Barato C & 3.51 & 1.51 & 0 \\
\hline & Barato E & 0.12 & 1.23 & 0 \\
\hline & longkwang & 4.60 & 2.86 & 0 \\
\hline & Kynshur & 1.81 & 1.09 & 0 \\
\hline & Mukroh A & 5.67 & 2.80 & 0 \\
\hline & Mukroh B & 3.87 & 5.24 & 0 \\
\hline & Saba & 3.69 & 1.19 & 0 \\
\hline Unadjusted average & & 3.40 & 2.25 & 0.46 \\
\hline \multirow[t]{11}{*}{ West Khasi Hills } & Khylemsangrin & 5.97 & 0.73 & 2.7 \\
\hline & Kriangrin & 0.22 & 0.00 & 0.33 \\
\hline & Kyndongnei & 2.14 & 0.00 & 0 \\
\hline & Langja & 3.78 & 0.14 & 0 \\
\hline & Mawlan B & 4.89 & 0.00 & 0 \\
\hline & Mawsikar & 0.78 & 0.21 & 0 \\
\hline & Nonglang & 23.74 & 10.96 & 0.48 \\
\hline & Pyndengsohstap & 7.09 & 0.00 & 0 \\
\hline & Siangra & 1.20 & 0.00 & 10.61 \\
\hline & Umthlu & 5.61 & 0.25 & 3.33 \\
\hline & Umwahlang & 3.80 & 0.18 & 0.52 \\
\hline Unadjusted average & & 5.38 & 1.13 & 1.63 \\
\hline
\end{tabular}

*West Jaintia Hills-Avg. Malaria Incidence for 2014, 2015, 2017

West Khasi Hills-Avg. Malaria Incidence for 2015-2017

reporting the covariate, showed significant positive associations of Plasmodium infection with presence of mosquitoes, presence of electricity, and absence of domestic animals (Table 7). A multivariate logistic regression model that controlled for various possible confounders did not result in any significant associations.

\section{Spatial distribution of village-level prevalence} of Plasmodium infected participants indicates spatial clustering in the West Khasi Hills

The geographic locations of each village, and the proportion of residents with $P$. falciparum infection (circle size) are shown in Fig. 4. In the West Jaintia Hills (Fig. 4a), only one village (Barato A) had any infections. In the West Khasi Hills (Fig. 4b), village-level infection prevalence ranged from 0 to $10.6 \%$. Significant clustering of infection (observed $=11$, expected $=2.15$, Relative Risk $(R R)=12.65 ; \mathrm{p}<0.001$ ) with a radius of $1 \mathrm{~km}$ was observed in southeastern part of the catchment area (Fig. 4b).

\section{Discussion}

This study investigated the spatial and temporal prevalence of Plasmodium infections among villages in two districts of Meghalaya state in northeast India in the context of recently declining malaria incidence. This is the first active surveillance-based report on malaria in the region using PCR-based methods to determine infection status. These community surveys occurred after a widespread distribution of LLINs throughout the region in 2016 that is believed to have contributed to declining malaria incidence recorded through PHC-based passive surveillance. Even with declining incidence, inter-annual variation among villages in Plasmodium infection prevalence was observed, along with risk factors that partly explain the patterns identified.

PHC data for the period 2014-2018 showed a general decline in the number of malaria cases, but this varied among villages. These results expand on the recent district-level decline described by Kessler et al. [4] by showing how some districts experienced little or no waning while others dropped quickly. Village-level information 
Table 4 Species of Anopheles mosquitoes captured during August - November 2018 in two villages of West Khasi Hills and three villages of West Jaintia Hills

\begin{tabular}{|c|c|c|c|c|c|c|c|}
\hline \multirow[t]{2}{*}{ Village (Month) } & \multicolumn{3}{|c|}{ West Khasi Hills } & \multicolumn{4}{|l|}{ West Jaintia Hills } \\
\hline & Kyrdum (Oct) & Nonglang (Nov) & $\begin{array}{l}\text { Total/10 } \\
\text { trap- } \\
\text { nights }\end{array}$ & Barato-A (Aug) & Barato-B (Aug-Nov) & $\begin{array}{l}\text { longkwang } \\
\text { (Nov) }\end{array}$ & $\begin{array}{l}\text { Total/10 } \\
\text { trap-nights }\end{array}$ \\
\hline ( $\mathrm{N}=$ HHs sampled) & $(\mathrm{N}=14)$ & $(\mathrm{N}=16)$ & - & $(\mathrm{N}=3)$ & $(\mathrm{N}=15)$ & $(\mathrm{N}=5)$ & - \\
\hline \multicolumn{8}{|l|}{ Anopheles species } \\
\hline jeyporiensis & 32 & 25 & 19.0 & 2 & 15 & 6 & 10.0 \\
\hline maculatus & 32 & 4 & 12.0 & 0 & 0 & 1 & 0.4 \\
\hline pseudowillmori & 6 & 6 & 4.0 & 0 & 2 & 1 & 1.3 \\
\hline nivipes & 0 & 0 & 0.0 & 0 & 4 & 1 & 2.2 \\
\hline philippinensis & 0 & 0 & 0.0 & 0 & 1 & 2 & 1.3 \\
\hline barbirostris & 0 & 0 & 0.0 & 0 & 0 & 1 & 0.4 \\
\hline dissidens & 0 & 0 & 0.0 & 0 & 1 & 0 & 0.4 \\
\hline nitidus & 1 & 0 & 0.3 & 0 & 0 & 2 & 0.9 \\
\hline peditaeniatus & 0 & 0 & 0.0 & 0 & 2 & 0 & 0.9 \\
\hline$x u i$ & 0 & 0 & 0.0 & 0 & 0 & 1 & 0.4 \\
\hline vagus & 0 & 0 & 0.0 & 5 & 1 & 0 & 2.6 \\
\hline splendidus & 1 & 5 & 2.0 & 0 & 0 & 0 & 0.0 \\
\hline jamesii & 0 & & 0.0 & 0 & 1 & 0 & 0.4 \\
\hline Total_all species & 72 & 40 & 37.3 & 7 & 27 & 15 & 21.3 \\
\hline $\begin{array}{l}\text { Total per trap-night-all } \\
\text { species }\end{array}$ & 5.1 & 2.5 & - & 2.3 & 1.8 & 3.0 & - \\
\hline
\end{tabular}

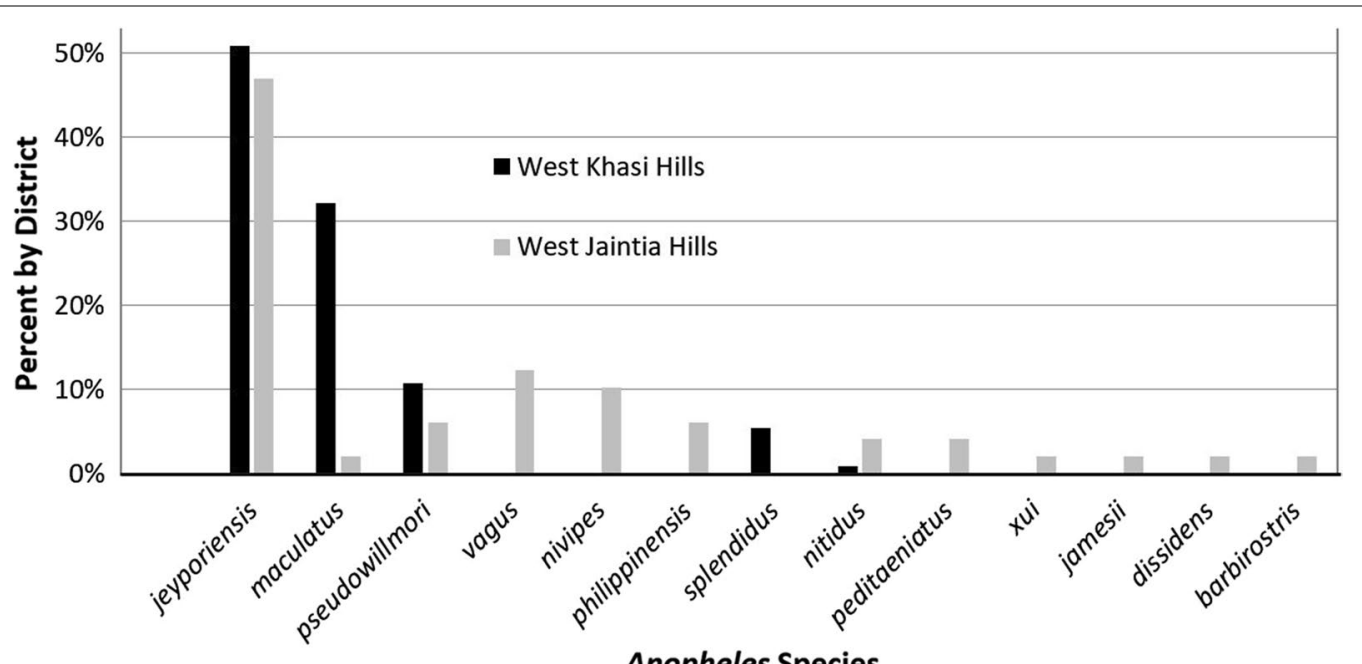

Fig. 3 Proportion of female Anopheles mosquitoes by species captured in the districts of West Jaintia Hills $(N=49)$ and West Khasi Hills $(N=112)$, Meghalaya, India, during August-November, 2018

on the government's LLIN programme indicates that LLINs were distributed in the West Jaintia Hills and West Khasi Hills survey villages during April 2016 and May 2016, respectively. The NVBDCP in Meghalaya reported that wide-scale distribution took place throughout 2016 in all districts of the state. Hence, the general decline in PHC-based incidence may be linked to increased use of LLINs, either alone or in combination with other prevention and control measures such as indoor residual spray (IRS). Studies conducted in India [15] have demonstrated 
Table 5 Village level household characteristics, West Jaintia Hills

\begin{tabular}{|c|c|c|c|c|c|c|c|c|c|}
\hline \multirow{2}{*}{$\begin{array}{l}\text { Variable } \\
\text { Characteristic }\end{array}$} & \multicolumn{9}{|c|}{ Percentage of HHs per Village by Variable and Characteristic } \\
\hline & Barato $\mathrm{A}$ & Barato B & Barato C & Barato $\mathrm{E}$ & longkwang & Kynshur & Mukroh A & Mukroh B & Saba \\
\hline \multicolumn{10}{|l|}{ Family members } \\
\hline $1-3$ & 18.7 & 32.3 & 12.3 & 11.4 & 28.1 & 7.0 & 20.0 & 26.5 & 16.7 \\
\hline $4-7$ & 68.2 & 54.8 & 78.5 & 74.3 & 68.8 & 79.0 & 75.0 & 64.7 & 63.3 \\
\hline$\geq 8$ & 13.1 & 12.9 & 9.2 & 14.3 & 3.1 & 14.0 & 5.0 & 8.8 & 20.0 \\
\hline \multicolumn{10}{|l|}{ Electricity } \\
\hline Yes & 78.5 & 91.9 & 55.4 & 34.3 & 0 & 74.4 & 48.6 & 32.4 & 40.0 \\
\hline No & 21.5 & 8.1 & 44.6 & 65.7 & 100 & 25.6 & 51.4 & 67.6 & 60.0 \\
\hline \multicolumn{10}{|l|}{ Toilet } \\
\hline Yes & 95.3 & 14.5 & 70.8 & 82.9 & 6.2 & 100 & 63.3 & 76.5 & 76.7 \\
\hline No & 4.7 & 85.5 & 29.2 & 17.1 & 93.8 & 0 & 36.7 & 23.5 & 23.3 \\
\hline \multicolumn{10}{|l|}{ Source of water supply } \\
\hline Indoor plumbing & 0.9 & 0 & 1.5 & 0 & 0 & 0 & 0 & 0 & 3.3 \\
\hline Open well & 98.1 & 100 & 96.9 & 100 & 100 & 100 & 100 & 100 & 96.7 \\
\hline Stream/river & 0 & 0 & 1.5 & 0 & 0 & 0 & 0 & 0 & 0 \\
\hline Public tap & 0.9 & 0 & 0 & 0 & 0 & 0 & 0 & 0 & 0 \\
\hline \multicolumn{10}{|l|}{ House wall material } \\
\hline Concrete/brick/stone & 63.5 & 41.9 & 35.4 & 42.8 & 37.5 & 39.5 & 46.6 & 58.8 & 40.0 \\
\hline Wood/Mud/thatched & 36.5 & 58.1 & 64.6 & 57.2 & 62.5 & 60.5 & 53.4 & 41.2 & 60.0 \\
\hline \multicolumn{10}{|l|}{ House roof material } \\
\hline Concrete/tiles & 10.3 & 3.2 & 0 & 2.9 & 0 & 0 & 0 & 8.8 & 0 \\
\hline Tin & 86.0 & 90.3 & 75.4 & 85.7 & 100 & 93.0 & 85.0 & 79.4 & 76.7 \\
\hline Thatched/others & 3.7 & 6.5 & 24.6 & 11.4 & 0 & 7.0 & 15.0 & 11.8 & 23.3 \\
\hline \multicolumn{10}{|l|}{ Domestic animals present } \\
\hline Yes & 53.3 & 50.0 & 78.5 & 65.7 & 37.5 & 81.4 & 55.0 & 44.1 & 73.3 \\
\hline No & 46.7 & 50.0 & 21.5 & 34.3 & 62.5 & 18.6 & 45.0 & 55.9 & 26.7 \\
\hline \multicolumn{10}{|l|}{ Mosquitos indoor } \\
\hline Yes, always & 41.1 & 61.3 & 78.5 & 68.6 & 43.8 & 67.4 & 45.0 & 44.1 & 70.0 \\
\hline Yes, sometimes & 15.9 & 38.7 & 12.3 & 31.4 & 56.2 & 32.6 & 11.7 & 55.9 & 23.3 \\
\hline Only rainy season & 43.0 & 0 & 9.2 & 0 & 0 & 0 & 43.3 & 0 & 6.7 \\
\hline \multicolumn{10}{|l|}{ Observed bed nets (N) } \\
\hline $1-4$ & 64.5 & 77.4 & 70.8 & 68.6 & 100 & 74.4 & 90.0 & 76.5 & 60.0 \\
\hline$\geq 4$ & 35.5 & 22.6 & 29.2 & 31.4 & 0 & 25.6 & 10.0 & 23.5 & 40.0 \\
\hline \multicolumn{10}{|l|}{ Households with ITN } \\
\hline Yes & 100 & 100 & 100 & 100 & 100 & 100 & 98.3 & 100 & 100 \\
\hline No & 0 & 0 & 0 & 0 & 0 & 0 & 1.7 & 0 & 0 \\
\hline \multicolumn{10}{|l|}{ IRS of $\mathrm{HH} /$ compound } \\
\hline Yes & 0.9 & 0 & 0 & 0 & 31.2 & 25.6 & 6.7 & 8.8 & 0 \\
\hline No & 99.1 & 100 & 100 & 100 & 68.8 & 74.4 & 93.3 & 91.2 & 100 \\
\hline \multicolumn{10}{|c|}{ Used $\geq$ preventive measure } \\
\hline Yes & 81.3 & 41.9 & 64.6 & 11.4 & 56.2 & 83.7 & 33.3 & 58.8 & 80.0 \\
\hline No & 18.7 & 58.1 & 35.4 & 88.6 & 43.8 & 16.3 & 66.7 & 41.2 & 20.0 \\
\hline \multicolumn{10}{|l|}{ Fever treated at PHC } \\
\hline Public & 99.1 & 100 & 100 & 100 & 100 & 100 & 98.3 & 100 & 100 \\
\hline Private & 0.9 & 0 & 0 & 0 & 0 & 0 & 1.7 & 0 & 0 \\
\hline
\end{tabular}




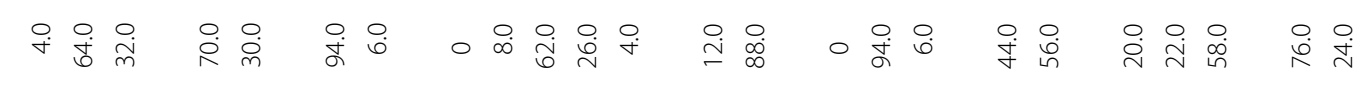

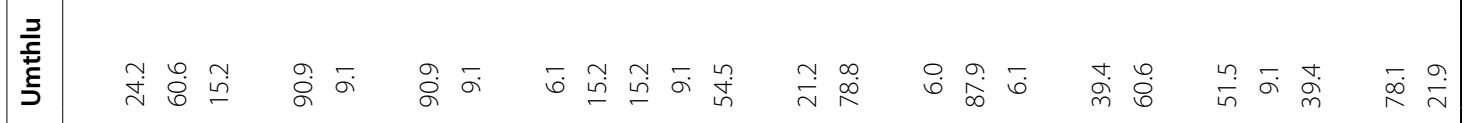

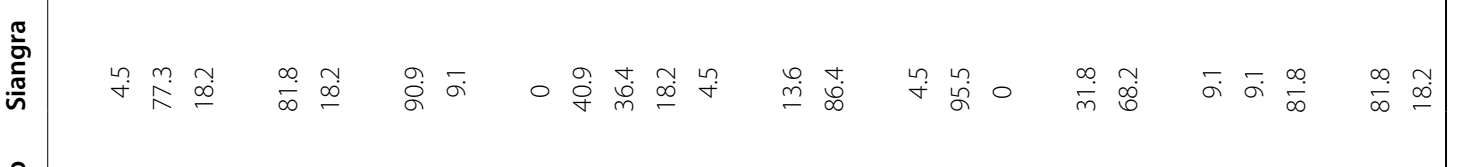

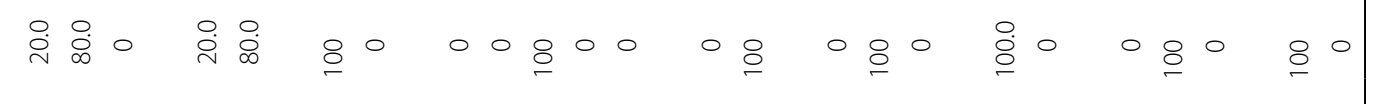

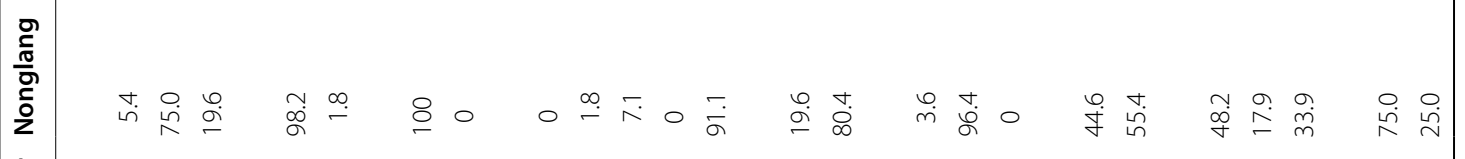

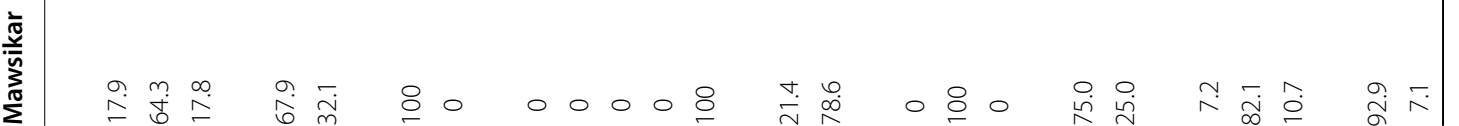

$\frac{\infty}{2}$

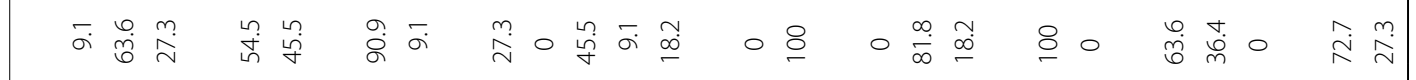

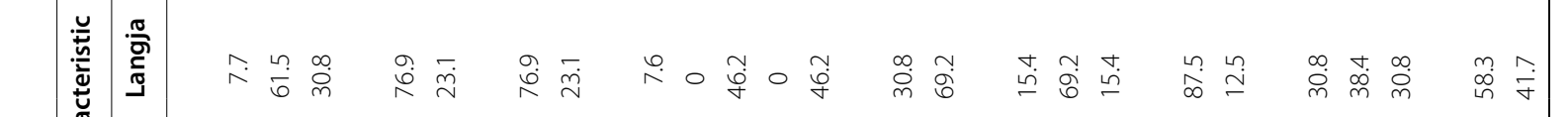

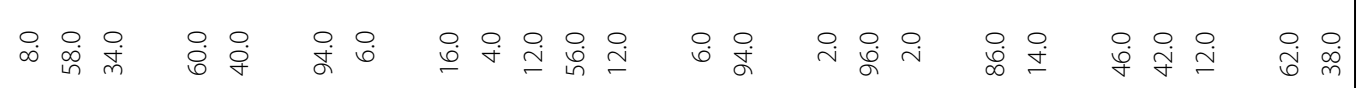

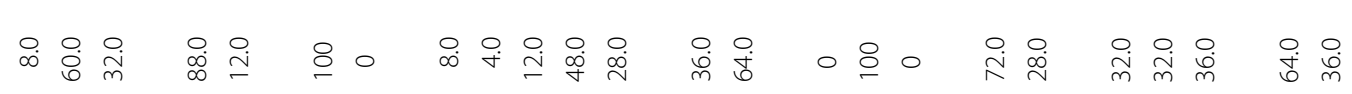

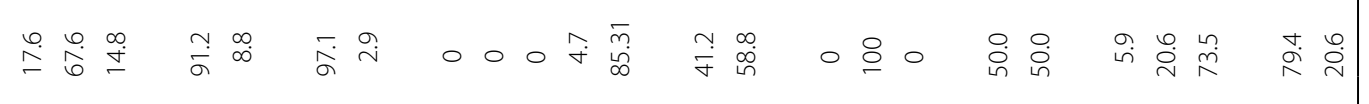

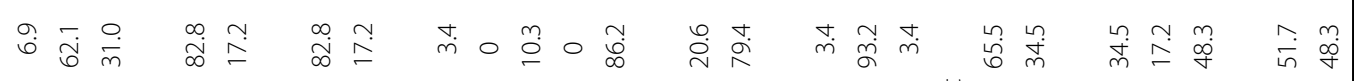

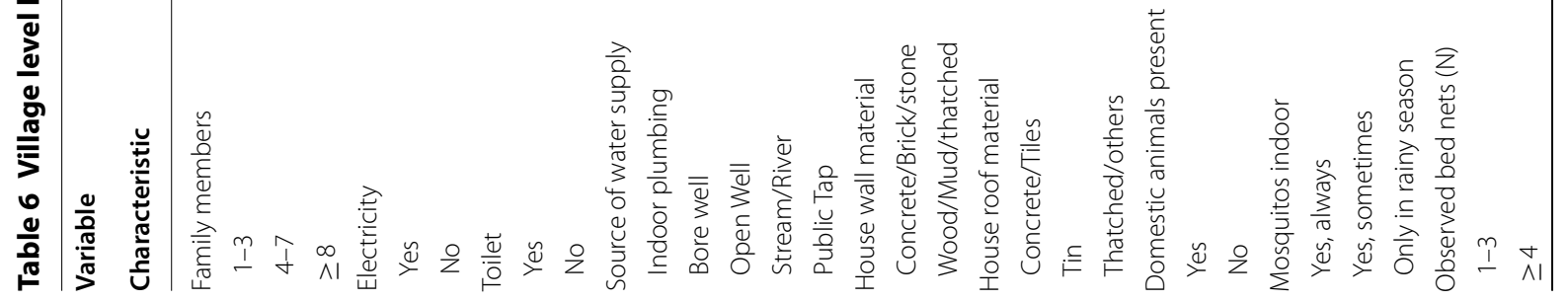




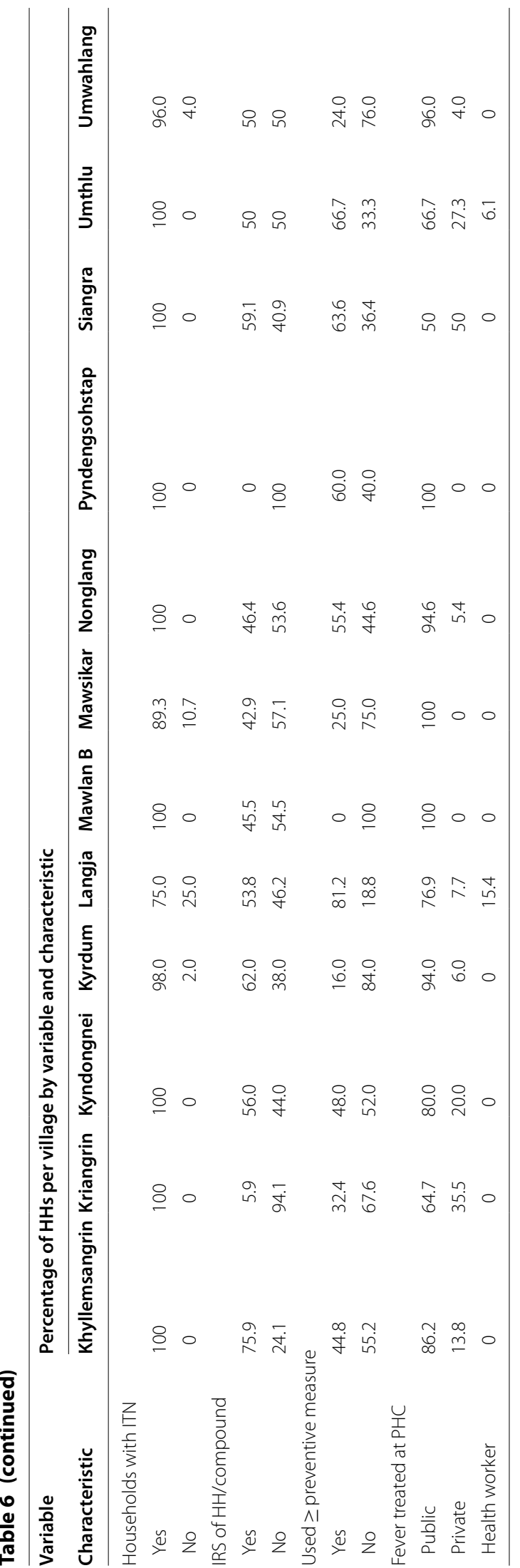


Table 7 Logistic regression of village-level risk factors for Plasmodium falciparum infection for 21 villages in West Khasi and West Jaintia Hills, Meghalaya, 2018

\begin{tabular}{lll}
\hline $\begin{array}{l}\text { Village characteristics }(\% \\
\text { of households) }\end{array}$ & Crude odds ratio $(\mathbf{9 5 \%} \mathrm{Cl})$ & $\boldsymbol{p}$-value \\
\hline Presence of electricity & $1.11(1.01,1.23)$ & 0.04 \\
Presence of toilet & $1.07(0.97,1.19)$ & 0.18 \\
Housing material: Wood & $1.01(0.96,1.07)$ & 0.64 \\
Roofing material: Thatched & $0.84(0.69,1.03)$ & 0.93 \\
Presence of animals & $0.91(0.84,0.99)$ & 0.03 \\
Mosquitoes & $1.19(1.12,1.39)$ & 0.03 \\
IRS sprayed & $0.16(0.99,1.07)$ & 0.16 \\
Net used by 1-3 people & $0.98(0.91,1.05)$ & 0.51 \\
Use of preventive measures & $1.01(0.97,1.05)$ & 0.62 \\
Animals kept inside the house & $0.95(0.87,1.01)$ & 0.10 \\
\hline
\end{tabular}

that use of LLINs and IRS [16] results in reduced malaria incidence. In India, LLINs have been evaluated for duration of effectiveness and acceptability, with very promising results. LLINs distributed in malaria-endemic communities of neighbouring state Assam during 20092013, for example, were found to be effective for up to three years, and community members recognized the protection benefits of these nets and regularly used them [17].

Another study during 2009 in Uttar Pradesh indicated that people considered LLINs to be safe, effective, and socially acceptable [18]. Investigations in central India (Chhattisgarh) during 2006-2007 demonstrated that Interceptor LLINs were highly effective in reducing $A n$. culicifacies densities and decreasing human malaria incidence [19]. Although LLINs are considered an effective malaria prevention tool in India, more detailed analyses of household- and individual-level level risk factors are needed to determine whether particular conditions or behaviours might help explain infection patterns that were observed among villages in this study [20,21].

Malaria diagnosis at the study PHCs, and throughout Meghalaya, is mainly performed using slide microscopy and RDTs. Due to declining Plasmodium transmission, microscopy and RDTs may not be sensitive enough to detect all cases of parasitaemia [22] resulting in underestimation of true prevalence, particularly if infection is increasingly subpatent and asymptomatic [23]. PCR detects more than twice the number of Plasmodium infections compared to microscopy and RDTs [24] and is very effective at detecting low-density infections [25]. In this study, current infection was determined by PCR to improve detection of low-level parasitaemia and/ or asymptomatic infections. As the number of new infections in the study region continue to decline, PCR

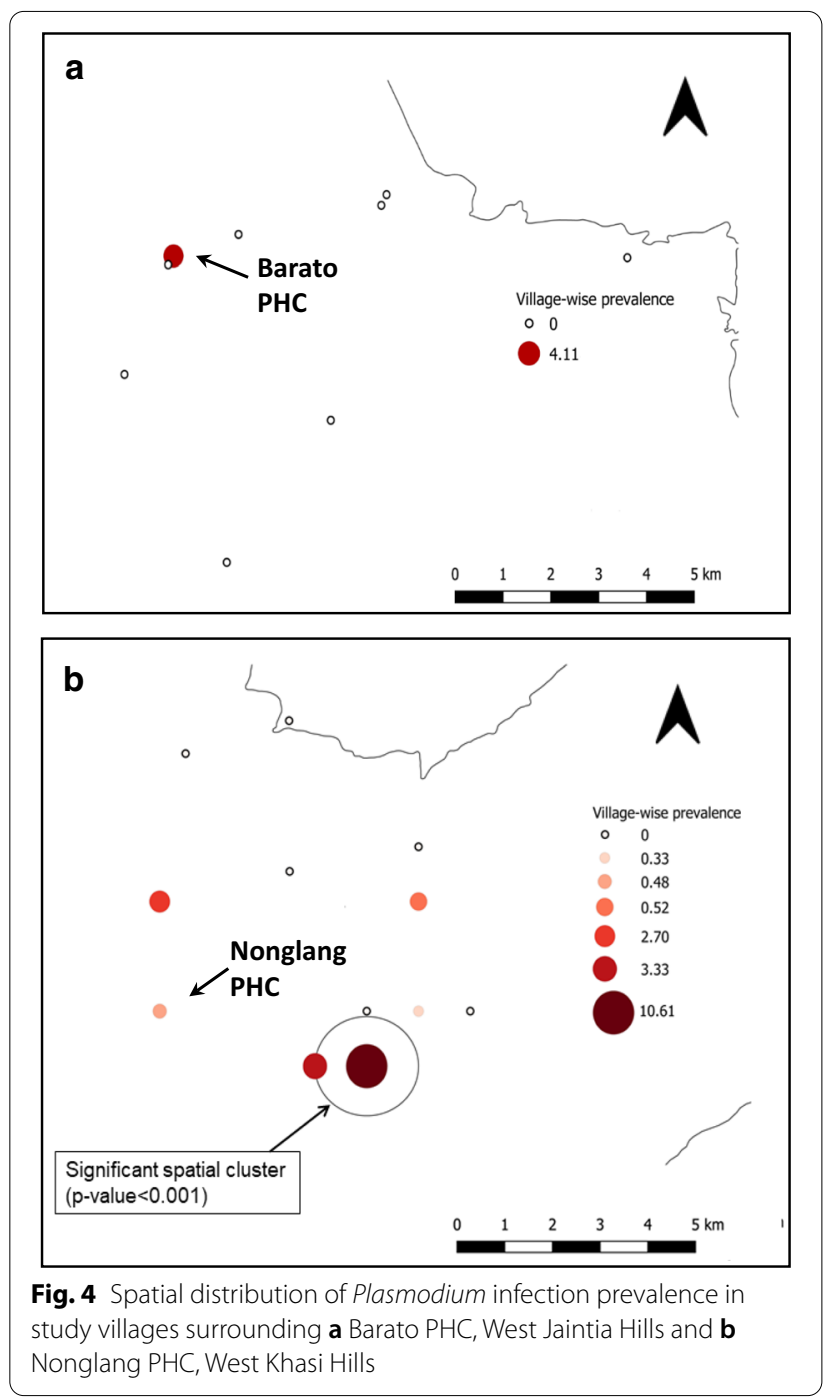

represents a more sensitive test [26] to better identify unrecognized, potentially infectious, carriers who can be treated, thereby reducing continued Plasmodium transmission. Indeed, elimination efforts in India will depend on improved diagnosis and treatment of asymptomatic infections combined with enhanced vector control and more focused disease surveillance [23, 27].

As a component of surveillance, analysis of spatial patterns can serve many purposes, including data exploration, visualizing configurations, defining spatial resolution, determining clusters, developing causal hypotheses, and more (e.g., [28]). In this study, a simple spatial statistical analysis was undertaken to evaluate village-level geographic clustering of Plasmodium infection prevalence. Similar spatial clustering of malaria village-level prevalence has been used in other regions, such as Ethiopia [29], Solomon Islands [30], and Bangladesh [31], but rarely in India [32]. Here, a small cluster of 
two villages was found in the southeastern part of West Khasi Hills. Otherwise, village-level prevalence was generally low and heterogeneously distributed. Nevertheless, village-level surveillance should play an important role in monitoring transmission as regional elimination possibilities increase [27].

Local environmental risk factors such as proximity to water bodies, elevation, topography, and land use/ land cover have been shown to explain spatial clustering of higher prevalence locations [33, 34]. The results presented here suggest that the use of spatial tools and satellite-derived environmental data might help policy makers to formulate targeted intervention strategies for future malaria control and elimination. More generally, where higher-incidence villages are clustered, anti-malarial interventions such as ITNs and IRS can be targeted to those persistent hot spots, eliminating wasteful spending $[30,35]$. However, interventions that reduce vector abundance and infection incidence will increase the challenge of identifying foci of transmission as incidence declines [30].

Villages with more households that kept domestic animals at the house had lower odds of Plasmodium infection, which is similar to findings in a study conducted in Zambia [36]. This finding, however, is in contrast to other research conducted in Indonesia [37] that suggested keeping livestock in the house increased malaria risk. Domestic animals may attract zoophilic mosquitoes away from humans, reducing people's exposure to infectious bites [38]. However, the availability of non-human blood meals often increases vector density and longevity [39], possibly enhancing malaria risk. Similarly, the presence of livestock animals nearby houses may increase the olfactory signal that attracts host-seeking female vectors, thereby increasing the risk of humans being bitten by infected mosquitoes. From the analyses, it is unclear why greater village-level presence of animals in the households studied here appeared to be protective, and more detailed analyses at the household level will be instructive. Where zoophilic vectors are abundant, existing vector control measures may be inadequate as part of efforts aimed at malaria elimination, and targeting livestock structures such as cattle sheds may increase the potential for malaria elimination [40].

Village-level Plasmodium infection prevalence was higher in villages with a greater proportion of households that had access to electricity. In some developing country settings, electricity availability is an indicator of higher SES, which is often related to lower risk of malaria. Most studies recognize malaria as a disease of poverty, as the malaria burden is often concentrated in the poorest continents and countries. In the study area, perhaps presence of electricity in these rural households attracts Anopheles vectors [41], thereby increasing the likelihood of transmission. Interestingly, a study conducted in Burkina Faso [42] showed that households with access to electricity were more likely to experience malaria. More detailed, household-level analyses are needed to better understand how presence of electricity might alter malaria risk.

Many other studies have revealed how different types of housing material used in the construction of roofs and walls are associated with malaria incidence [42]. However, in this study, no association between roof and wall materials was found which is consistent with the results from other studies [23]. In contrast, investigations in Assam, India [43] demonstrated that malaria incidence was higher among people residing in bamboo houses. The lack of association of housing material in this study may be attributable to little variation across these variables. Alternatively, house construction materials may be less important if biting often occurs outside or if LLINs are widely and properly used. More generally, focused studies are needed on specific features of housing and socio-economic development that reduce malaria risk in different contexts.

Studies conducted in India [20] have shown that the lack of mosquito prevention methods at the village level, such as use of ITNs or IRS, are risk factors for malaria. Curiously, the village-level prevalence of mosquito prevention efforts (e.g., coils, ITNs or IRS) was not associated with Plasmodium infection prevalence. Perhaps there was insufficient variation among villages in use of these prevention measures [44] or possibly inadequate or improper application. Finer-scale analyses at the household level (e.g., [44]) are needed to further investigate the impacts of these interventions [30].

A total of 13 Anopheles species were captured despite limited sampling. This is consistent with previous studies in the region that have identified a high diversity of anophelines, some of which were involved in malaria transmission [13, 45-48]. These potential vectors, many of which are broadly zoo-anthropophilic, are found in diverse habitats and specifically forest-fringe and ricegrowing environments. Anopheles species diversity was greater in the West Jaintia Hills than in the West Khasi Hills. This may be because the former is relatively warmer and at generally lower elevation, but further studies in other villages and seasons are needed to determine if this is a general pattern. The predominance of An. jeyporiensis, which has not often been reported in the region in recent years, is noteworthy.

Two species historically considered as primary vectors in the region, An. baimaii and An. minimus, were not identified in the samples, which corroborates more extensive recent studies in northeast India that these forest-associated mosquito species are in decline [47, 48]. 
There is growing concern that species previously considered to be secondary vectors may be playing an increasingly important role in malaria transmission though this remains to be characterised [3]. In this respect, An. jeyporiensis and An. maculatus are of particular concern as they were the most abundant species in this study and both have been reported to be infected with $P$. falciparum in this region, specifically: An. jeyporiensis in Assam [49] and Bangladesh [45] and in studies from 80 years ago, An. maculatus from Assam and Meghalaya [50, 51]. In the context of changing malaria epidemiology due to deforestation and increased LLIN use, further studies are needed to determine which species are now contributing to malaria transmission and to characterize their biological attributes relevant to vector control including biting-time, host-preference, larval ecology, and seasonal abundance.

Although this study offers important findings, it also has some limitations. First, it was not possible to evaluate all possible risk factors that may contribute to the geographic variation in Plasmodium infection risk and the presence of disease clustering, such as Anopheles mosquito abundance and distribution, distances from houses to water bodies or rice paddies, or elevation. Second, no data on weather variables such as temperature, precipitation, and/or humidity were included, which could alter vector-human contact and impact malaria parasite prevalence [52]. Finally, although this study focused on two districts of Meghalaya, it is difficult to generalize findings to the entire state or other parts of north-east India [3].

\section{Conclusion}

This study demonstrated that malaria incidence has recently declined perhaps in part due to the widespread introduction of control strategies, especially LLINs. Nevertheless, temporal and spatial variation has left some villages at higher risk, making efforts aimed at regional elimination more difficult. Therefore, anti-malarial interventions should be continued, even expanded, if the government goal of malaria elimination by 2030 is to be achieved. The second round of state-wide LLIN distribution in Meghalaya was scheduled for 2020 but paused due to the COVID-19 pandemic. Malaria-prevention education for people of all ages in these communities should be pursued through different educational mediums. Because of cross-border movement of people and parasites [53, 54], the goal of malaria elimination in India must be a multinational, regional effort $[2,55]$. More detailed risk factor analysis at the household and individual levels, combined with expanded environmental and spatial analyses, should help to detect high risk settings and "silent" transmission areas, thereby assisting the NVBDCP and government policy makers to plan, design, and streamline malaria preventive measures.

\section{Abbreviations}

API: Annual parasite index; ASHA: Accredited social health activist; ITNs: Insecticide-treated nets; IRS: Indoor residual spray; LLINs: Long-lasting insecticidetreated bed nets; NVBDCP: National Vector Borne Disease Control Programme; PCR: Polymerase chain reaction; PHC: Primary health centre.

\section{Acknowledgements}

We thank the Department of Health, Government of Meghalaya and the Meghalaya State Programme Management Unit, NVBDCP for access to malaria surveillance data. Specifically, we would like to acknowledge former Additional Chief Secretary Shri PW Ingty IAS, former Health Secretary Shri Pravin Bakshi IAS, and M\&E consultant Larry Kharbamon for facilitating data sharing and providing the API maps of Meghalaya. We also thank field staff Phiban Lyngdoh, Christine Manar, Manroi Challam, Enrichson Suting, Watson Siangshai, Jurysha Nongdhar, Charisma Khongwir, Peter Marbaniang, Alman Kshiar, Oling Lamin, and Fourness Amdep, and lab staff Zachariah Sunn and Innang Sangriang at IIPH-Shillong, and Preeti Acharya at ICMR-NIRTH. We also thank New York University MPH student Natsumi Nemoto for support with sample quality control and repeating concentrated PCRs.

\section{Authors' contributions}

$A V E, A K, S A$, and JC conceived and designed the active surveillance study; RL provided access to Meghalaya State Malaria Control Programme data; BS, AVE, AK, and JC undertook the PHC and ASHA data collection; BS and MLW cleaned the data and performed analyses; BK undertook DNA extractions and PCR amplifications for the active surveillance study; USS, AD, and CW planned and undertook the mosquito work; BS, MLW, AK, SA, and JC wrote the manuscript with input from all authors. All authors read and approved the final manuscript.

\section{Funding}

Research reported in this publication was supported by the National Institute of Allergy and Infectious Diseases of the National Institutes of Health under Award Number U19A1089676 as part of the International Centers of Excellence for Malaria Research. The content is solely the responsibility of the authors and does not necessarily represent the official views of the National Institutes of Health.

\section{Availability of data and materials}

Data generated in this study will be made available through the open-access online resource for population-based epidemiological studies ClinEpiDB (https ://clinepidb.org). Meghalaya State Malaria Control Programme provided the state malaria surveillance data.

\section{Ethics approval and consent to participate}

Ethical approval for the study was obtained from the Institutional Review Boards (IRBs) of Martin Luther Christian University, Shillong, Meghalaya, India and New York University, New York, NY, USA. Written informed consent was obtained from all the participants who were 18 years of age or older. Assent was obtained for the participants aged 7-17 years in addition to parental consent.

\section{Consent for publication}

Not applicable.

\section{Competing interests}

The authors declare that they have no competing interests.

\section{Author details}

${ }^{1}$ Center for Genomics and Systems Biology, Department of Biology, New York University, New York, NY 10003, USA. ${ }^{2}$ Indian Institute of Public Health-Shillong, Shillong, Meghalaya 793001, India. ${ }^{3}$ Martin Luther Christian University, Shillong, Meghalaya 793006, India. ${ }^{4}$ Department of Earth and Environmental Sciences, School of Natural Sciences, University of Manchester, Manchester M13 9PT, UK. ${ }^{5}$ Department of Health Services (Malaria), National Vector Borne Disease Programme, Lawmali, Pasteur Hill, Shillong, Meghalaya 
793001, India. ${ }^{6}$ ICMR-National Institute of Research in Tribal Health, Jabalpur, Madhya Pradesh 482003, India. ${ }^{7}$ Department of Epidemiology, School of Public Health, University of Michigan, Ann Arbor, MI 48109, USA. ${ }^{8}$ Department of Epidemiology, College of Global Public Health, New York University, New York, NY 10012, USA.

Received: 9 December 2020 Accepted: 20 January 2021 Published online: 04 February 2021

\section{References}

1. World Health Organization. World Malaria Report 2018. Geneva: World Health Organization; 2018.

2. Guerin PJ, Dhorda M, Ganguly NK, Sibley CH. Malaria control in India: A national perspective in a regional and global fight to eliminate malaria. J Vector Borne Dis. 2019;56:41-5.

3. Sarma DK, Mohapatra PK, Bhattacharyya DR, Chellappan S, Karuppusamy B, Barman K, et al. Malaria in North-east India: importance and implications in the era of elimination. Microorganisms. 2019;7:1-21.

4. Kessler A, Van Eijk AM, Jamir L, Walton C, Carlton JM, Albert S. Malaria in Meghalaya: a systematic literature review and analysis of data from the National Vector-Borne Disease Control Programme. Malar J. 2018;17:411.

5. Demas A, Oberstaller J, DeBarry J, Lucchi NW, Srinivasamoorthy G, Sumari D, et al. Applied genomics: data mining reveals species-specific malaria diagnostic targets more sensitive than 18S rRNA. J Clin Microbiol. 2011;49:2411-8

6. Collins FH, Paskewitz SM. A review of the use of ribosomal DNA (rDNA) to differentiate among cryptic Anopheles species. Insect Mol Biol. 1996;5:1-9.

7. Walton C, Somboon P, O'Loughlin SM, Zhang S, Harbach RE, Linton YM, et al. Genetic diversity and molecular identification of mosquito species in the Anopheles maculatus group using the ITS2 region of rDNA. Infect Genet Evol. 2007;7:93-102.

8. Folmer OM, Black W, Hoeh W, Lutz R, Vrijenhoek R. DNA primers for amplification of mitochondrial cytochrome c oxidase subunit I from diverse metazoan invertebrates. Mol Mar Biol Biotechnol. 1994;3:294-9.

9. Kearse M, Moir R, Wilson A, Stones-Havas S, Cheung M, Sturrock S, et al. Geneious Basic: an integrated and extendable desktop software platform for the organization and analysis of sequence data. Bioinformatics. 2012;28:1647-9.

10. Ratnasingham S, Hebert PDN. BOLD: the barcode of life data system. Mol Ecol Notes. 2007;7:355-64.

11. Kulldorff M, Nagarwalla N. Spatial disease clusters: statistics and inference. Stat Med. 1995;14:799-810.

12. Kulldorff M. A spatial scan statistic. Commun Stat Theory Methods. 1997;26:1481-96.

13. Fang Y, Shi WQ, Zhang Y. Molecular phylogeny of Anopheles hyrcanus group members based on ITS2 rDNA. Parasit Vectors. 2017;10:417.

14. Wilai P, Namgay R, Ali RSM, Saingamsook J, Saeung A, Junkum A, et al. A multiplex PCR based on mitochondrial coi sequences for identification of members of the Anopheles barbirostris complex (Diptera: Culicidae) in Thailand and other countries in the region. Insects. 2020;11:409.

15. Chourasia MK, Kamaraju R, Kleinschmidt I, Bhatt RM, Swain DK, Knox TB, et al. Impact of long-lasting insecticidal nets on prevalence of subclinical malaria among children in the presence of pyrethroid resistance in Anopheles culicifacies in Central India. Int J Infect Dis. 2017:57:123-9.

16. Sahu SS, Thankachy S, Dash S, Nallan K, Swaminathan S, Kasinathan G, et al. Evaluation of long-lasting indoor residual spraying of deltamethrin 62.5 SC-PE against malaria vectors in India. Malar J. 2020. https://doi. org/10.1186/s12936-020-3112-4

17. Dev V, Barman K, Khound K. A cross-sectional study assessing the residual bio-efficacy and durability of field-distributed long-lasting insecticidal nets in malaria endemic ethnic communities of Assam. Northeast India J Infect Public Health. 2016;9:298-307.

18. Sood RD, Mittal PK, Kapoor N, Razdan RK, Dua VK, Dash AP. Community awareness, perceptions, acceptability and preferences for using LLIN against malaria in villages of Uttar Pradesh. India J Vector Borne Dis. 2010;47:243-8.
19. Bhatt RM, Sharma SN, Uragayala S, Dash AP, Kamaraju R. Effectiveness and durability of Interceptor long-lasting insecticidal nets in a malaria endemic area of central India. Malar J. 2012;11:189.

20. Sharma PK, Ramanchandran R, Hutin YJ, Sharma R, Gupte MD. A malaria outbreak in Naxalbari, Darjeeling district, West Bengal, India, 2005: weaknesses in disease control, important risk factors. Malar J. 2009;8:288.

21. Stresman G, Bousema T, Cook J. Malaria hotspots: is there epidemiological evidence for fine-scale spatial targeting of interventions? Trends Parasitol. 2019:35:822-34.

22. Baum E, Sattabongkot J, Sirichaisinthop J, Kiattibutr K, Jain A, Taghavian $\mathrm{O}$, et al. Common asymptomatic and submicroscopic malaria infections in Western Thailand revealed in longitudinal molecular and serological studies: a challenge to malaria elimination. Malar J. 2016;15:333.

23. van Eijk AM, Sutton PL, Ramanathapuram L, Sullivan SA, Kanagaraj D, Priya GSL, et al. The burden of submicroscopic and asymptomatic malaria in India revealed from epidemiology studies at three varied transmission sites in India. Sci Rep. 2019;9:17095.

24. Okell LC, Bousema T, Griffin JT, Ouédraogo AL, Ghani AC, Drakeley CJ. Factors determining the occurrence of submicroscopic malaria infections and their relevance for control. Nat Commun. 2012:3:1237.

25. Johnston SP, Pieniazek NJ, Xayavong MV, Slemenda SB, Wilkins PP, Da Silva AJ. PCR as a confirmatory technique for laboratory diagnosis of malaria. J Clin Microbiol. 2006;44:1087-9.

26. Nair CB, Manjula J, Subramani PA, Nagendrappa PB, Manoj MN, Malpani $S$, et al. Differential diagnosis of malaria on Truelab Uno ${ }^{\circledR}$, a portable, real-time, MicroPCR device for point-of-care applications. PLOS ONE. 2016:11:e0146961.

27. Ghosh SK, Rahi M. Malaria elimination in India - The way forward. J Vector Borne Dis. 2019;56:32-40.

28. Fritz CE, Schuurman N, Robertson C, Lear S. A scoping review of spatial cluster analysis techniques for point-event data. Geospat Health. 2013;7:183-98.

29. Yeshiwondim AK, Gopal S, Hailemariam AT, Dengela DO, Patel HP. Spatial analysis of malaria incidence at the village level in areas with unstable transmission in Ethiopia. Int J Health Geogr. 2009;8:5.

30. Burkot TR, Bugoro H, Apairamo A, Cooper RD, Echeverry DF, Odabasi D, et al. Spatial-temporal heterogeneity in malaria receptivity is best estimated by vector biting rates in areas nearing elimination. Parasit Vectors. 2018;11:606.

31. Haque U, Sunahara T, Hashizume M, Shields T, Yamamoto T, Haque R, et al Malaria prevalence, risk factors and spatial distribution in a Hilly forest area of Bangladesh. PLOS ONE. 2011;6:e18908.

32. Prakash A, Mohapatra PK, Bhattacharyya DR, Sharma CK, Goswami BK, Hazarika NC, et al. Epidemiology of malaria outbreak (April/May, 1999) in Titabor Primary Health Center, district Jorhat (Assam). Indian J Med Res. 2000;111:121-6.

33. Canelas T, Castillo-Salgado C, Ribeiro H. Systematized literature review on spatial analysis of environmental risk factors of malaria transmission. Adv Infect Dis. 2016;6:52-62

34. Machault V, Vignolles C, Borchi F, Vounatsou P, Pages F, Briolant S, et al. The use of remotely sensed environmental data in the study of malaria. Geospat Health. 2011;5:151-68.

35. Conn JE, Norris DE, Donnelly MJ, Beebe NW, Burkot TR, Coulibaly MB, et al. Entomological monitoring and evaluation: diverse transmission settings of ICEMR projects will require local and regional malaria elimination strategies. Am J Trop Med Hyg. 2015;93:28-41.

36. Bulterys PL, Mharakurwa S, Thuma PE. Cattle, other domestic animal ownership, and distance between dwelling structures are associated with reduced risk of recurrent Plasmodium falciparum infection in southern Zambia. Trop Med Int Health. 2009;14:522-8.

37. Hasyim H, Dhimal M, Bauer J, Montag D, Groneberg DA, Kuch U, et al. Does livestock protect from malaria or facilitate malaria prevalence? A cross-sectional study in endemic rural areas of Indonesia. Malar J. 2018:17:302.

38. Asale A, Duchateau L, Devleesschauwer B, Huisman G, Yewhalaw D. Zooprophylaxis as a control strategy for malaria caused by the vector Anopheles arabiensis (Diptera: Culicidae): a systematic review. Infect Dis Poverty. 2017;6:160

39. Saul A. Zooprophylaxis or zoopotentiation: the outcome of introducing animals on vector transmission is highly dependent on the mosquito mortality while searching. Malar J. 2003;2:32 
40. Waite JL, Swain S, Lynch PA, Sharma SK, Haque MA, Montgomery J, et al. Increasing the potential for malaria elimination by targeting zoophilic vectors. Sci Rep. 2017;7:40551.

41. Barghini A, de Medeiros BAS. Artificial lighting as a vector attractant and cause of disease diffusion. Environ Health Perspect. 2010;118:1503-6.

42. Yamamoto S, Louis VR, Sié A, Sauerborn R. Household risk factors for clinical malaria in a semi-urban area of Burkina Faso: a case-control study. Trans R Soc Trop Med Hyg. 2010;104:61-5.

43. Yadav K, Dhiman S, Rabha B, Saikia PK, Veer V. Socio-economic determinants for malaria transmission risk in an endemic primary health centre in Assam. India Infect Dis Poverty. 2014;3:19.

44. Van Eijk AM, Ramanathapuram L, Sutton PL, Peddy N, Choubey S, Mohanty $S$, et al. The use of mosquito repellents at three sites in India with declining malaria transmission: surveys in the community and clinic. Parasit Vectors. 2016;9:418

45. Alam MS, Chakma S, Khan WA, Glass GE, Mohon AN, Elahi R, et al. Diversity of anopheline species and their Plasmodium infection status in rural Bandarban, Bangladesh. Parasit Vectors. 2012;5:150

46. Srivastava AK, Kharbuli B, Shira DS, Sood A. Effect of land use and land cover modification on distribution of anopheline larval habitats in Meghalaya. India J Vector Borne Dis. 2013;50:121-6.

47. Akhtar N, Nagpal BN, Kapoor N, Srivastava A, Valecha N. Role of An. culicifacies as a vector of malaria in changing ecological scenario of Northeastern states of India. J Vector Borne Dis. 2016;53:264-71.

48. Yadav K, Dhiman S, Rabha B, Goswami D, Saikia PK, Veer V. Disappearance of An. minimus and An. dirus from certain malaria endemic areas of Assam. India J Arthropod Borne Dis. 2017:11:27-35.
49. Prakash A, Bhattacharyya DR, Mohapatra PK, Mahanta J. Role of the prevalent Anopheles species in the transmission of Plasmodium falciparum and P. vivax in Assam state, north-eastern India. Ann Trop Med Parasitol. 2004;98:559-68.

50. Anderson LAP, Viswanathan DK. The Assam medical research society, Shillong. A Résumé of its Activities during 1931-41. Calcutta: Thacker Spink \& Co; 1941

51. Viswanathan DK, Das S, Oommen AV. Malaria-carrying Anophelines in Assam, with special reference to the results of twelve months' dissections. J Malar Inst India. 1941;4:297-306.

52. Addisu A, Tegegne Y, Mihiret Y, Setegn A, Zeleke AJ. A 7-year trend of malaria at primary health facilities in Northwest Ethiopia. J Parasitol Res. 2020;2020:420487.

53. Wangdi K, Gatton ML, Kelly GC, Banwell C, Dev V, Clements ACA. Malaria elimination in India and regional implications. Lancet Infect Dis. 2016:16:e214-24.

54. Lal AA, Rajvanshi H, Jayswar H, Das A, Bharti P. Malaria elimination: using past and present experience to make malaria-free India by 2030. J Vector Borne Dis. 2019;56:60-5.

55. Park KS, Malik SK, Lee JH, Karim AM, Lee SH. Malaria elimination in India and regional implications. Front Microbiol. 2018;9:2016-8.

\section{Publisher's Note}

Springer Nature remains neutral with regard to jurisdictional claims in published maps and institutional affiliations.
Ready to submit your research? Choose BMC and benefit from:

- fast, convenient online submission

- thorough peer review by experienced researchers in your field

- rapid publication on acceptance

- support for research data, including large and complex data types

- gold Open Access which fosters wider collaboration and increased citations

- maximum visibility for your research: over 100M website views per year

At BMC, research is always in progress.

Learn more biomedcentral.com/submissions 